\title{
Erratum to: Recognising Global Interdependence Through Disasters
}

\author{
Anthony Reid
}

\section{Erratum to:}

Chapter 2 in: M.A. Miller et al. (eds.), Crossing Borders, https://doi.org/10.1007/978-981-10-6126-4_2

The original version of this chapter was inadvertently published with incorrect impacts of natural disasters affect percentage on Asia region in Table 2.1 (Page no. 36). The correct percentage is $88.7 \%$. 